\begin{tabular}{|c|c|c|}
\hline 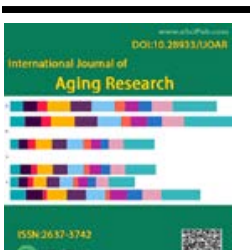 & $\begin{array}{l}\text { International Journal of Aging Research } \\
\text { (ISSN:2637-3742) }\end{array}$ & 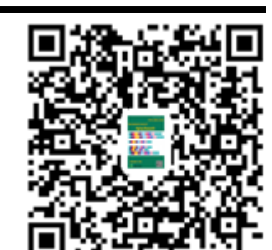 \\
\hline
\end{tabular}

\title{
Primary Prevention of Alzheimer's Disease in Indonesia
}

\section{Yuda Turana ${ }^{1}$, Jeslyn Tengkawan ${ }^{1}$, Ika Suswanti ${ }^{1}$, DY Suharya ${ }^{2}$, Woro Riyadina ${ }^{3}$, Julianti Pradono $^{3}$}

${ }^{1}$ Faculty of Medicine and Health Sciences, Atma Jaya Catholic University of Indonesia

${ }^{2}$ Alzheimer Disease International

${ }^{3}$ National Institute of Health Research and Development, Ministry of Health, Republic of Indonesia

\begin{abstract}
Indonesia is the fourth most populous country in the world. An increase number in the proportion of elders is accompanied by an increase of degenerative diseases and disabilities, including Alzheimer's disease (AD). Prevalence of dementia in Indonesia is 1.2 million cases in 2015 and will keep increasing up to 3,980,000 in 2050. This study discusses data on the prevalence of dementia's risk factors in Indonesia, calculates population-attributable risks (PAR) to identify the number of dementia cases that could be prevented, and determines which intervention strategies will have the most significant effect in reducing Alzheimer's Disease (AD) cases. Prevalence of potentially modifiable risk factors for $A D$ such as low education, hypertension, diabetes, obesity, and mental disorders are still high. Moreover, the prevalences keep increasing for the last five years. Low education has the highest estimated PAR, which could significantly lower new AD cases if it is being improved. Ten and thirty percent of risk factor reduction can decrease AD cases by 18,000 and 66,000 cases. In addition, reducing physical inactivity by $10 \%$ and $30 \%$ can reduce 19,000 and 55,000 cases of $A D$ respectively; lowering $10 \%$ prevalence of midlife hypertension and diabetes can reduce 2400 and 1600 cases of AD. Decreasing $10 \%$ of all risk factors is estimated to reduce 22,000 of new AD cases. By reducing these modifiable risk factors, especially by improving access to education, the incidence of AD could be greatly reduced. This review is expected to give suggestion to the government in determining the priority scale of controlling risk factors for reducing the social and economic burden caused by AD.
\end{abstract} *Correspondence to Author: Yuda Turana, MD, PhD, Departement of Neurology, Faculty of Medicine and Health Sciences, Atma Jaya Catholic University of Indonesia, Pluit Raya 2, Jakarta 14440, Indonesia.

How to cite this article:

Yuda Turana, Jeslyn Tengkawan, Ika Suswanti, DY Suharya, Woro Riyadina, Julianti Pradono. Primary Prevention of Alzheimer's Disease in Indonesia. International Journal of Aging Research, 2019, 2:40

Keywords: Alzheimers Disease, Prevalence, Risk Factors 


\section{Introduction}

Indonesia ranks fourth as the largest population in the world. ${ }^{1}$ Similar to other countries, Indonesia is experiencing an ageing population, which projected population is estimated to increase by $10 \%$ in $2020,15.8 \%$ in 2035 and $18.4 \%$ in $2050 .{ }^{2}$ The increase in the proportion of the elderly will undoubtedly be accompanied by an increase in degenerative diseases and disability, including Alzheimer's disease (AD). The estimated dementia cases in Indonesia is 1.2 million cases in 2015 and it is estimated to increase around $1,894,000$ cases in 2030 and will continue to $3,980,000$ in $2050 .^{3}$

The main concern of degenerative brain diseases such as $A D$ is the unavailability of effective treatment until now. ${ }^{3,4}$ In the midst of increasing public awareness of $A D$ and the absence of effective drugs, effective prevention strategies need to be improved. It is known that by slowing down one-year onset of symptoms can reduce the prevalence of $A D$ over 9 million cases for the next 40 years. ${ }^{4}$

Various studies have shown several potential modifiable risk factors for $A D$, including diabetes, hypertension, obesity, smoking, sedentary life, depression and low education. $^{4,5}$ In this paper, we will discuss the data on the prevalence of dementia's risk factors in Indonesia, calculates populationattributable risks (PAR) to identify the number of dementia cases that could be prevented and determines which intervention strategies will give the most significant effect in reducing Alzheimer's Disease (AD) cases.

In this article, estimated PAR associated with midlife diabetes, hypertension, obesity, physical inactivity, smoking, depression, and low educational level in Indonesia was used. This study also shows the effect of each risk factor in reducing the incidence of future $A D$ cases.

\section{Methods}

\section{Data on dementia's risk factors in Indonesia}

Data on dementia's risk factors were taken from basic health research data (Riskesdas). Riskesdas is a national health data that is taken periodically every five years, which represents an overview of national, provincial and district/city data, and can be downloaded free on the Internet. The indicators include health status and health determinants. Riskesdas data collection in 2013 included 11,986 census blocks (BS) from 12,000 BS targeted (99.9\%), in 33 provinces and 497 cities/districts. ${ }^{6}$ The data on disease prevalence was determined based on the history of non-communicable disease (NCD) symptoms and/or diagnosis. Hypertension was diagnosed through interview (diagnostic history by health professionals and consumption of antihypertensive drugs) and measurements.

\section{Statistics}

\section{PAR calculation}

PAR is the proportion of people suffering from disease in a population that can be attributed to a given risk factor, assuming that there is a causal relation. PAR was calculated using Levin's formula:

$P A R=\frac{P \times(R R-1)}{1+P \times(R R-1)}$

$P$ is the population prevalence of the risk factor and RR is relative risk. We also calculated the combined adjusted data with the account of non-independence risk factors. Discussion on PAR can be found in several source articles. ${ }^{4,5}$ In calculating the PAR, Riskesdas 2013 was used for the prevalence data, while RR calculation data was taken based on several meta-analysis research sources, cited in a study conducted by Norton S. et al. ${ }^{5}$

The prevalence of dementia's risk factors, such as midlife diabetes, midlife hypertension, obesity, smoking, and physical inactivity, were obtained from Riskesdas 2013. The data on depression was not explicitly listed, but data of 
emotional, mental disorders that contain questions about aspects of depression was collected as well. The prevalence of diabetes mellitus (DM) was not obtained through blood glucose testing, rather, it was solely based on previous doctor's diagnosis or diabetes drugs administration or diabetes symptoms $(2.9 \%)$. Therefore, it is likely that the prevalence might show a lower number than it should be.

The prevalence of hypertension was obtained through history and measurement blood pressure (14.6\%). Prevalence of diabetes was taken on 25-74 years age group. While the prevalence data of midlife hypertension used the age group of $35-64$. Prevalence of obesity based on the adult nutritional status of population aged of more than 18 years was taken according to Body Mass Index (BMI) $\geq 27,0(15.4 \%){ }^{6}$

The data on physical activity were collected by asking the frequency of activities in the past week for more than ten years old population. Vigorous physical activity is defined as an activity that requires hard physical effort and causes significant increases in breathing or heart rate, (e.g., drawing water, climbing, running, cutting trees, hoeing, etc.) for a minimum of three days a week with total duration of 75 minutes per week, or $\geq 1500$ MET-minutes. MET-minutes of vigorous physical activity is the length of time (minutes) of activity in a week multiplied by 8 calories. Moderate physical activity (sweeping, mopping, etc.) is an activity that requires moderate physical effort and causes small increases in breathing or heart rate, at least five days or more with a total duration of activity 150 minutes per week. Other than these two conditions are categorized in light physical activity. ${ }^{7}$ The prevalence of physical inactivity is $26.1 \%$. The possibility of depressive symptoms was assessed through the Self Reporting Questionnaire (SRQ) consisting of 20 question items perfomed on the population of $\geq 15$ years. The data collected using the SRQ instrument has several limitations that it is only revealed an individual's emotional status for a limited time ( \pm 30 days) and it is not designed to diagnose specific mental disorders. Prevalence of depression / emotional, mental disorder was $6 \%$. Tobacco used in the calculation of prevalence was only through smoking, with a prevalence of $24.3 \%$. Another risk factor for dementia is low education. Based on the 20122013 social and economic survey data, it was seen that as many as $15.41 \%$ of people did not complete elementary school and as many as $28.37 \%$ graduated from elementary school, which means almost a half $(43.78 \%)$ of Indonesia adult population has a low educational level. ${ }^{8}$

In this study, we also estimated the total number of $A D$ cases attributable to the prevalence of $A D$ in the present. Since Indonesia does not have national dementia prevalence data, it estimates the number of people with dementiausing the estimation from Alzheimer Disease International data, which is $1,200,000$ by $2015 .^{3}$ Similar to a study by Barnes DE et al , we also calculated the number of cases that could have been prevented if the risk factors prevalence were lower than 10\%, 20\% and 30\%. ${ }^{4}$ Moreover, $95 \%$ confidence interval (Cl) was used to measure RR estimation and PAR estimation, which are the number of attributable cases and the number of cases potentially prevented.

\section{Results}

In this study, the highest estimated PAR are low education, smoking and physical inactivity. This means that if these three risk factors can be reduced by 10 percent of their prevalence, the impact of reducing the incidence of new $A D$ could be the most significant (table 1,2). Low education contributes to the highest incidence of $A D$ in Indonesia (risk factor in 246,000 AD cases). If the low educational level prevalence was $10 \%$ lower than at present, we estimated that around 18,000 cases of $A D$ could potentially be prevented; moreover, reduction from low education of $30 \%$ could potentially prevent about 66.000 cases of AD in Indonesia. 
Table 1. AD cases attributable to potential modifiable risk factors in Indonesia

\begin{tabular}{llllll}
\hline Indonesia & Prevalence & \multicolumn{2}{l}{ PAR $^{\star}(\mathbf{9 5} \% \mathbf{C l})$} & \multicolumn{2}{l}{ Number of attributable cases $^{\star *}$} \\
\hline Diabetes mellitus & $2.9 \%$ & $1.3 \%$ & $(0.6-2.2)$ & 15.6 & $(7.2-26.4)$ \\
\hline Midlife hypertension & $14.6 \%$ & $8.2 \%$ & $(2.3-15.3)$ & 98.4 & $(27.6-183.6)$ \\
\hline Midlife obesity & $15.4 \%$ & $8.5 \%$ & $(5.0-12.4)$ & 102 & $(60-148.8)$ \\
\hline Physical inactivity & $26.1 \%$ & $17.6 \%$ & $(4.7-31.7)$ & 211.2 & $(56.4-380.4)$ \\
\hline Depression & $6.0 \%$ & $3.8 \%$ & $(2.5-5.2)$ & 45.6 & $(30-62.4)$ \\
\hline Smoking & $24.3 \%$ & $12.5 \%$ & $(3.5-22.6)$ & 150 & $(42-271.2)$ \\
\hline Low educational level & $43.8 \%$ & $20.5 \%$ & $(13.3-27.4)$ & 246 & $(159.6-328.8)$ \\
\hline Combined & --- & $54.3 \%$ & $(28.3-73.6)$ & 651.6 & $(339.6-883.2)$ \\
\hline Adjusted combined & --- & $31.4 \%$ & $(15.6-45.7)$ & 376.8 & $(187.2-548.4)$ \\
\hline
\end{tabular}

${ }^{*} \mathrm{PAR}=$ population-attributable risk ${ }^{*} 95 \% \mathrm{Cl}$; in thousands

Table 2. Estimated number of $A D$ cases that could be prevented through risk factors reduction in Indonesia

\begin{tabular}{llll}
\hline Indonesia & $\mathbf{1 0}$ \% reduction & $\mathbf{2 0 \%}$ reduction & $\mathbf{3 0 \%}$ reduction \\
\hline Diabetes mellitus & 1.600 & 3600 & 4.800 \\
\hline Midlife hypertension & 2.400 & 14.000 & 26.000 \\
\hline Midlife obesity & 6.000 & 18.000 & 30.000 \\
\hline Physical inactivity & 19.000 & 31.000 & 55.000 \\
\hline Depression & 4.900 & 9.600 & 9.600 \\
\hline Smoking & 12.000 & 30.000 & 42.000 \\
\hline Low educational level & 18.000 & 42.000 & 66.000 \\
\hline Adjusted combined & 22.000 & 52.000 & 88.000 \\
\hline
\end{tabular}

The PAR estimation for physical inactivity is about $17.6 \%$. This means that the physical inactivity is a "direct" risk factor for the incidence of $211.000 \mathrm{AD}$ cases. If physical inactivity prevalence was $10 \%$ lower than at present, we estimate that about 19.000 AD cases in Indonesia could be prevented and $30 \%$ of dementia prevalence reduction could potentially prevent about 55.000 cases in Indonesia.

The PAR estimation for diabetes is about $1.3 \%$ $(15,600 \mathrm{AD}$ cases) in Indonesia, which imply that diabetes is also a "direct" risk factor for the incidence of 15,600 AD cases. Reducing diabetes prevalence by $10 \%$ could prevent $1.600 \mathrm{AD}$ cases in Indonesia, and reducing $30 \%$ of diabetes prevalence could potentially prevent about 4,800 cases in Indonesia. As it is known that this estimatation may be minimal, considering that the diagnosis was only based on history taking.

The PAR estimataion for obesity is about 8.5 $\%$. Reducing obesity prevalence by $10 \%$ could prevent $6.000 \mathrm{AD}$ cases. The PAR estimation for midlife hypertension is $8.2 \%(98.400)$. If midlife hypertension prevalence was $10 \%$ lower than a present, we estimated that 2,400 AD cases could be prevented in Indonesia, so does 
with other risk factors (table 2). This study also performed the calculation of PAR combination and PAR adjusted combination. In PAR combination, the value seemed quite high. However, given the various risk factors interacting with each other (e.g. physical inactivity, obesity, hypertension, DM are often related to one another), this study was also using PAR adjusted combination. ${ }^{4}$ It was found that these seven factors as the risk factors for AD incidence of 376,800 cases and 10 percent reduction in the prevalence of these risk factors could reduce 22,000 new AD incidence (table 2).

\section{Discussion}

In this study, Riskesdas data was used as a reference to show the prevalence of NCD in Indonesia. Riskesdas does not only focus on district/city but also describes national health prevalence, for each region in Indonesia has complex differences in characteristics and culture. Therefore, Riskesdas national prevalence data could represent Indonesia characteristics in general.

The national prevalence of diabetes based on diagnosis and symptoms is $2.1 \%$, with a great difference prevalence in each province ranges from $0.8 \%-3.7 \%$. The prevalence of diabetes based on diagnosis and symptoms shows lower results compared to other countries such as in Malaysia and Brunei. ${ }^{9,10}$ The prevalence of diabetes in Indonesia tends to be higher on people with higher education levels, and those living in urban areas. ${ }^{6}$ When looking at the potential risk reduction for Alzheimer's disease, diabetes has a lower PAR compared to other risk factors.

The prevalence used in this study was in the midlife age group of 35-64, making it difficult to compare with the prevalence in other countries. However, the prevalence of hypertension in Indonesia based on the age of 18 years and above was 26.5 percent, with various prevalence in each province $(16.8 \%-30.9 \%)$. ${ }^{6}$ Compared with the 2013 Riskesdas data, the prevalence of hypertension has increased from
$26.5 \%$ to $34.1 \%$ in $2018.6,11$ This data shows similar findings to other countries in Southeast Asia, such as Malaysia, Myanmar, Philippines and Vietnam. 12-17. The systematic study of population in 90 countries shows a higher prevalence of hypertension in low and middleincome countries $(31.5 \%)$ than high-income countries $(28.5 \%)$ worldwide ( $\mathrm{P}$-value $=0.001)$, this study shows a low proportion of awareness, treatment, and control of hypertension in low and middle-income countries. ${ }^{18}$ When looking at this data, the declines in the prevalence of hypertension in the low-middle-income countries reduce the prevalence of $A D$ significantly.

Obesity contributes to the emergence of several vascular risk factors that indirectly increase dementia cases. Obesity can be attributed to the relatively high level of physical inactivity / sedentary lifestyle. Based on Riskesdas data, $15.4 \%$ of the population over 18 years old are obese. While the proportion for the population above ten years with activities of a minimum of $\geq 6$ hours/day is $24.1 \%{ }^{6}$

In Riskesdas 2013, the criteria for "active" physical activity are individuals who carry out a heavy or moderate physical activity or both, while the criteria for "less active" are individuals who do less than moderate physical activity. The proportion of physical activity classified as less active in general is 26.1 percent. However, the proportion of sedentary lifestyle is six hours longer in women, people with low education, unemployed, and living in urban areas. ${ }^{6}$ The study conducted by Katzmarzyk $P$ and Lee in 2012 shows that reducing sedentary lifestyle up to 3 hours per day can increase life expectancy. ${ }^{19}$ While another study shows that elimination of physical inactivity would increase the life expectancy of the world population by 0.68 (range 0.41-0.95) years. ${ }^{20}$

The current proportion of smokers in Indonesia is 29.3 percent. The highest proportion of daily active smokers at the age of 30-34 years is 33.4 percent, age 35-39 years 32.2 percent, while the proportion of daily active smokers are 
Yuda Turana et al., IJOAR, 2019 2:40

more common in males than females. ${ }^{12-17}$ Based on the occupations, farmers/fishers/laborers are the most significant proportion of daily active smokers (44.5\%) compared to other occupational groups. Around $80 \%$ of the 1.1 billion smokers worldwide live in low and middle-income countries, where the burden of tobacco-related-illness and death is the heaviest. ${ }^{21}$ Increasing smoking behavior is inseparable with the country policy to control tobacco consumption in its country. World Health Organization (WHO) shows only 1 in 3 countries, representing $39 \%$ of the world's population, monitors tobacco use by conducting national representative youth and adult surveys at least once every five years. ${ }^{21}$

Smoking is the second largest of $A D$ risk factors after low education. In this study, it was found that if $20 \%$ reduction in the prevalence of smoking, it can prevent 30,000 cases of AD. The proportion of people aged $\geq 15$ years who smoked and chewed tobacco tend to increase, from $34.2 \%$ in 2007 to $36.3 \%$ in 2013 . The data showed a quite alarming trend, in which age $10-19$ smokers reached $11.7 \%$. The number of smokers in Indonesia currently ranks third in the world following China and India, with the proportion reaching 35 percent of the total population, or about 75 million people. The mechanism of cigarettes as a risk factor of $A D$ through vascular disease and hundreds of neurotoxins in cigarettes smoke contribute to $A D$ incidence.

Low education contributes to the highest incidence of $A D$ in Indonesia (risk factor in 246,000 AD cases). Although the 9-year compulsory basic education program has been declared since 1994, low education is still high $(44 \%){ }^{8}$ If the low education prevalence was $10 \%$ lower than at present, we estimated that about 18,000 cases of $A D$ could potentially be prevented in Indonesia. The research data in Jogjakarta showed that elderly without formal education nearly $35 \%$ were exposed to dementia, but those who completed nine years education and more, were affected less than 10 percent of dementia. ${ }^{22}$

Based on this Riskesdas data, the prevalences of obesity in Indonesia continue to increase. The prevalence of obesity in men in 2010 was $7.8 \%$ and increased to $19.7 \%$ in 2013. Similarly, obesity in women increased from $17.5 \%$ in 2010 to $32.9 \%$ in $2013 .{ }^{6}$ In this study obesity was estimated as a risk factor in 102,000 cases of $A D$. If the prevalence of obesity could be reduced by $10 \%$, it would prevent the incidence of 6000 new AD cases. Besides, reducing $20 \%$ of the prevalence could prevent 18,000 new cases. So, reducing the case of obesity and increasing physical activity can prevent the new incidence of dementia is a meaningful way.

The general principle is that dementia is caused by various proportions of modifiable risk factors, regardless of the prevalence. This modifiable risk factors data can be translated into the effects of the global burden of dementia, which can have implications for social and economic costs. It is never too late for public health interventions to push back onset in many cases for up to several years. The prevalence of dementia may be reduced by half if the onset is delayed by five years. ${ }^{4}$ Although we may not expect modification of risk factors to give a considerable impact, any reduction in dementia risk would be a great achievement. ${ }^{3,4}$

It is seen that more than 30 percent of $A D$ cases were come from modifiable risk factors. This study focuses on $A D$ as most cases of RR calculations and studies in the community are directed at $A D$, as the most common type of dementia. However, it is also known that the risk factors for $A D$ and other dementia are almost the same. In this study, if the prevalence of all seven risk factors were $10 \%$ lower, there would be as many as 22.000 fewer cases in Indonesia, and if the risk factor prevalence were $30 \%$ lower, AD potentially could be reduced by 88.000 in Indonesia.

Risk factors for AD: Comparison of Riskesdas 2013 and 2018

IJOAR: https://escipub.com/international-journal-of-aging-research/ 
In mid-2018, the results of the analysis of several data of Riskesdas RI 2018 were released. Although the Riskesdas 2018 data showed improvement in poor nutritional status in infants, there was a trend of increase in the proportion of obesity in adults since 2007 as follows: 10.5\% (Riskesdas 2007), $14.8 \%$ (Riskesdas 2013) and $21.8 \%$ (Riskesdas 2018). Likewise, various noncommunicable diseases have increased such as stroke, diabetes mellitus and hypertension. The prevalence of stroke rose from $7 \%$ to $10.9 \%$; diabetes mellitus from $6.9 \%$ to $8.5 \%$, and hypertension from $25.8 \%$ to $34.1 \% .{ }^{23}$ The increase in the prevalence of non-communicable diseases was related to lifestyle, including smoking, consumption of alcohol, physical activity, and consumption of fruits and vegetables. Since 2013 the prevalence of smoking in adolescents (10-18 years) continues to increase, which is $7.2 \%$ (Riskesdas 2013), 8.8\% (Sirkesnas 2016) and $9.1 \%$ (Riskesdas 2018). Data on the proportion of alcoholconsumption also increased from $3 \%$ to $3.3 \%$, the proportion of sedentary lifestyle was also increased from $26.1 \%$ to $33.5 \%$ and the increase in the proportion of mental disorders in the Riskesdas 2018 data was quite significant when compared to Riskesdas 2013, from $1.7 \%$ to $7 \% .{ }^{11}$

\section{Conclusion}

Prevalence of potential modifiable risk factors of $A D$ such as hypertension, diabetes, obesity, and mental disorders are still high. Moreover, their prevalences keep increasing for the last five years. Low education has the highest estimated PAR, which could significantly lower new $A D$ cases if it is improved. By reducing these modifiable risk factors, especially improving access to education, incidence of $A D$ could be significantly reduced. Through PAR calculations, the result of this study is expected to give suggestion to the government in determining the priority scale of controlling risk factors in reducing the prevalence of $A D$ and in reducing the economic burden caused by AD.

\section{REFERENCES}

1. Total Population by Country 2018 [Internet]. [cited 2018 Dec 21]. Available from: http://worldpopulationreview.com/countries/

2. Adioetomo SM, Cicih LM, Asmanedi, Toersilaningsih R. Menjadi lansia tangguh: antara anugerah dan tantangan. In: Memetik bonus demografi membangun manusia sejak dini. Rajawali Pers; 2018. p. 299.(In Bahasa)

3. Prince M, Wimo A, Guerchet M, Ali G-C, Wu Y-T, Prina M, et al. World Alzheimer Report 2015 The Global Impact of Dementia: An analysis of prevalence, incidence, cost and trends. London; 2015.

4. Barnes DE, Yaffe K. The projected effect of risk factor reduction on Alzheimer's disease prevalence. Lancet Neurol. 2011 Sep;10(9):81928.

5. Norton S, Matthews FE, Barnes DE, Yaffe K, Brayne C. Potential for primary prevention of Alzheimer's disease: an analysis of populationbased data. Lancet Neurol. 2014 Aug 1;13(8):788-94.

6. Ministry of Health and National Institute of Health Research and Development. National report on basic health research, Riskesdas, 2013. Jakarta, Indonesia, 2014 (and additional analysis).

7. NCDs | Global Physical Activity Surveillance [Internet]. WHO. [cited 2018 Dec 21]. Available from:

http://www.who.int/ncds/surveillance/steps/GPA Q/en/

8. Indonesia National Socioeconomic Survey 2013 | GHDx [Internet]. [cited 2018 Dec 21]. Available from:

http://ghdx.healthdata.org/record/indonesianational-socioeconomic-survey-2013

9. WHO | Diabetes country profiles 2016 [Internet]. WHO. [cited 2018 Dec 22]. Available from: http://www.who.int/diabetes/country-profiles/en/

10. Roglic G, World Health Organization, editors. Global report on diabetes. Geneva, Switzerland: World Health Organization; 2016. 86 p.

11. Ministry of Health and National Institute of Health Research and Development. National report on basic health research, Riskesdas, 2018. Jakarta, Indonesia, 2018.

12. WHO Global Health Observatory data repository. Prevalence of raised fasting blood glucose crude estimate, age-standardized [Internet]. WHO. 2014 [cited 2018 Dec 17]. Available from: 
http://apps.who.int/gho/data/view.main.2520?lan $\mathrm{g}=\mathrm{en}$

13. WHO Global Health Observatory data repository. Prevalence of obesity among adults, BMI $\geq 30$, age-standardized [Internet]. WHO. 2014 [cited 2018 Dec 17]. Available from: http://apps.who.int/gho/data/view.main.CTRY245 $0 A$ ?lang=en

14. WHO Global Health Observatory data repository. Raised blood pressure (SBP $\geq 140$ OR DBP $\geq$ 90), age-standardized [Internet]. WHO. 2014 [cited 2018 Dec 17]. Available from: http://apps.who.int/gho/data/view.main.NCDBPA REGv?lang=en

15. WHO Global Health Observatory data repository. Tobacco use, data by country in 2015 [Internet]. WHO. 2015 [cited 2018 Dec 17]. Available from: http://apps.who.int/gho/data/view.main.1805?lan $\mathrm{g}=\mathrm{en}$

16. WHO Global Health Observatory data repository. Prevalence of insufficient physical activity among adults, age-standardized [Internet]. WHO. 2015 [cited 2018 Dec 17]. Available from: http://apps.who.int/gho/data/view.main.2463?lan $\mathrm{g}=\mathrm{en}$

17. WHO Global Health Observatory data repository. Suicide rate estimates by country, agestandardized [Internet]. WHO. 2015 [cited 2018 Dec 17]. Available from: http://apps.who.int/gho/data/view.main.MHSUICI DEASDRv?lang=en

18. Mills KT, Bundy JD, Kelly TN, Reed JE, Kearney PM, Reynolds K, et al. Global Disparities of Hypertension Prevalence and Control: A Systematic Analysis of Population-based Studies from 90 Countries. Circulation. 2016 Aug 9;134(6):441-50.

19. Katzmarzyk PT, Lee I-M. Sedentary behaviour and life expectancy in the USA: a cause-deleted life table analysis. BMJ Open. 2012 Jan $1 ; 2(4): e 000828$.

20. Lee I-M, Shiroma EJ, Lobelo F, Puska P, Blair SN, Katzmarzyk PT, et al. Effect of physical inactivity on major non-communicable diseases worldwide: an analysis of burden of disease and life expectancy. Lancet Lond Engl. 2012 Jul $21 ; 380(9838): 219-29$.

21. Tobacco [Internet]. [cited 2018 Dec 17]. Available from: https://www.who.int/news-room/factsheets/detail/tobacco

22. Suriastini NW, Turana $Y$, Witoelar F, Sikoki B, Wicaksono T, Mulyanto ED. The Prevalence, Risk Factors of Dementia and Caregiver
Knowledge of The Early Symptoms: Evidence from a large-scale survey in Yogyakarta [Internet]. IUSSP - 2017 International Population Conference. [cited $2018 \mathrm{Dec} 8$ ]. Available from: https://iussp.confex.com/iussp/ipc2017/meetinga pp.cgi/Paper/4311

23. Kementerian Kesehatan Republik Indonesia. Potret Sehat Indonesia dari Riskesdas 2018 [Internet]. 2018 [cited 2018 Dec 22]. Available from:

http://www.depkes.go.id/article/view/1811020000 3/potret-sehat-indonesia-dari-riskesdas2018.html 